\title{
Particulate matter and daily mortality and hospital admissions in the west midlands conurbation of the United Kingdom: associations with fine and coarse particles, black smoke and sulphate
}

\author{
H R Anderson, S A Bremner, R W Atkinson, R M Harrison, S Walters
}

\begin{abstract}
Objectives-There is considerable evidence linking ambient particles measured as particulate matter with aerodynamic diameter $<10 \mu \mathrm{m}\left(\mathbf{P M}_{10}\right)$ to daily mortality and hospital admissions but it is not clear which physical or chemical components of the particle mixture are responsible. The relative effects of fine particles $\left(\mathbf{P M}_{2.5}\right)$, coarse particles $\left(\mathbf{P M}_{2,5-10}\right)$, black smoke (mainly fine particles of primary origin) and sulphate (mainly fine particles of secondary origin) were investigated, together with ozone, $\mathrm{SO}_{2}, \mathrm{NO}_{2}$, and $\mathrm{CO}$, on daily mortality and hospital admissions in the west Midlands conurbation of the United Kingdom.
\end{abstract}

Methods-Time series of health outcome and environmental data were obtained for the period 1994-6. The relative risk of death or hospital admission was estimated with regression techniques, controlling for long term time trends, seasonal patterns, influenza epidemics, effects of day of the week, and temperature and humidity. Models were adjusted for any remaining residual serial correlation and overdispersion. The sensitivities of the estimates for the effects of pollution to the inclusion of a second pollutant and seasonal interactions (warm or cool) were also examined.

Results-Daily all cause mortality was not associated with any gaseous or particulate air pollutant in the all year analysis, although all measures of particles apart from $\mathbf{P M}_{2.5-10}$ showed significant positive effects of the warm season. Neither respiratory nor cardiovascular admissions (all ages) were associated with any air pollutant, and there were no important seasonal interactions. However, analysis of admissions by age found evidence for various associations-notably between $\mathbf{P M}_{10}$, $\mathbf{P M}_{2.5}$, black smoke, $\mathbf{S O}_{2}$, and ozone (negative) and respiratory admissions in the 0-14 age group. The coarse fraction, $\mathbf{P M}_{2.5-10}$ differed from $\mathbf{P M}_{2.5}$ in having smaller and less consistent associations (including several large significant negative associations) and a different lag distribution. The results for black smoke, an indicator of fine primary carbonaceous particles, were very similar to those for $\mathbf{P M}_{2.5}$, and tended to be more robust in two pollutant models. The effects of sulphate, an indicator of secondary particles, also showed some similarities to those of $\mathbf{P M}_{2.5}$. Conclusions-Clear effects of air pollution on mortality and hospital admissions were difficult to discern except in certain age or diagnostic subgroups and seasonal analyses. It was also difficult to distinguish between different measures of particles. Within these limitations the results suggest that the active component of $\mathbf{P} \mathbf{M}_{10}$ resides mostly in the fine fraction and that this is due mainly to primary particles from combustion (mainly vehicle) sources with a contribution from secondary particles. Effects of the coarse fraction cannot be excluded.

(Occup Environ Med 2001;58:504-510)

Keywords: air pollution particulates; mortality; hospital admissions

There is substantial evidence linking concentrations of inhalable ambient particles (particulate matter with aerodynamic diameter $<10 \mu \mathrm{m}$ $\left.\left(\mathrm{PM}_{10}\right)\right)$ at concentrations below current guidelines with short term effects on daily mortality and morbidity. ${ }^{1-3}$ Scientific and regulatory interest is now focusing on those components of the particle fraction which are likely to be most toxic. It has been postulated that toxicity may lie in the fine $\left(\mathrm{PM}_{2.5}\right)$ and ultrafine $\left(\mathrm{PM}_{0.1}\right)$ fractions of $\mathrm{PM}_{10}$ as these contain the greatest number of particles and exhibit a higher deposition fraction in the peripheral lung than the coarse fraction $\left(\mathrm{PM}_{2.5-10}\right)$. The role of different particle components is difficult to confirm with available scientific methods. In particular, epidemiological studies are currently limited by a lack of adequate time series of size fractionated particles. It is known that sulphuric acid aerosol, sulphate, and black smoke, all of which are found mainly in the fine fraction are associated with short term health effects. However, this does not exclude an effect of the coarse fraction which comprises substantially fewer particles than the fine fraction and is deposited in the larger as well as the smaller intrathoracic airways. The distinction is important because fine particles arise directly or indirectly from combustion sources, whereas the coarse fraction tends to be dominated by re-suspended crustal materials and sea salt. ${ }^{4}$ Studies which have compared the effects of the fine and coarse fractions on daily mortality or hospital admissions, have reported inconsistent 
results, with some showing greater effects of fine particles, ${ }^{5}$ some showing no clear differences, ${ }^{6-9}$ and some suggesting a stronger effect of coarse particles. ${ }^{10}$ A meta-analysis of daily mortality in 29 cities points towards $\mathrm{PM}_{2.5}$ being more important. ${ }^{11}$ Some panel studies suggest that fine particles are more important, ${ }^{12} 13$ and others find little difference between the effects of fine and coarse particles. ${ }^{14}$ Taken together, the current evidence suggests that although fine particles are consistently associated with acute health effects, an effect of coarse particles cannot be dismissed.

In the first European investigation of its kind, we considered the associations between a range of particle measures $\left(\mathrm{PM}_{10}, \mathrm{PM}_{2.5}\right.$, $\mathrm{PM}_{2.5-10}$, sulphate, and black smoke) and daily mortality (all causes, cardiovascular, and respiratory), and hospital admissions (respiratory and cardiovascular), in the west Midlands region of the United Kingdom. The emissions inventory for the west Midlands conurbation attributes $57 \%$ of $\mathrm{PM}_{10}$ emissions to road traffic, within which the greatest contribution comes from heavy duty and other diesel fuelled vehicles. The other major contributing source category is industrial combustion (27\%), although this represents emissions predominantly from high level sources which impact at ground level far less than the emissions from road traffic. ${ }^{4}$ Our aims were: (a) to see if any of these measures of particles were associated with short term health effects, $(b)$ to identify differences, if any, between the fine and coarse fractions, and (c) to compare the effects of sulphate (a secondary fine particle) with those of black smoke (a primary fine particle). This paper summarises the results of many analyses. The full reports will be available through the world wide web.

\section{Methods}

The area of study was the west Midlands conurbation of the United Kingdom which contains a population of 2.3 million and includes the city of Birmingham. Because of the earliest availability of $\mathrm{PM}_{2.5}$ data, the study period was constrained to the 27 month period between October 1994 and December 1996. Counts of daily deaths and emergency hospital admissions for those people resident in and dying or admitted to hospitals in the study area were obtained from the Office for National Statistics. Daily counts of mortality were constructed for all causes excluding external causes (ninth revision of the international classification of diseases (ICD-9<800), respiratory causes (ICD-9 460-519) and cardiovascular causes (ICD-9 390-459). Daily counts of hospital admissions were constructed for respiratory and cardiovascular diagnoses divided by age $(0-14,15-64, \geqslant 65)$ and the following subdiagnoses: cardiac disease (ICD-9 390-429); ischaemic heart disease (ICD-9 410-414); stroke (ICD-9 430-438); asthma (ICD-9 493); and chronic obstructive pulmonary disease (ICD-9 490-492, 494-496).

Air pollution data were obtained from AEA Technology for all background monitoring sites with data on at least $75 \%$ of days. For some monitors it was possible to fill in small numbers of missing values with a weighted average of the values from other monitoring stations. The pollution values from all stations providing data were then averaged to provide single estimates of the daily concentrations for each pollutant. The particle measures were $\mathrm{PM}_{10}$ (three sites), $\mathrm{PM}_{2.5}$ (one site), black smoke (three sites), sulphate $\left(\mathrm{SO}_{4}{ }^{2-}\right)$, (mean of the two nearest rural sites), and $\mathrm{PM}_{2.5-10}$ (obtained by subtraction using the co-located $\mathrm{PM}_{2.5}$ and $\mathrm{PM}_{10}$ site). Of $\mathrm{PM}_{2.5}$ measurements $18 \%$ were missing, mainly at the end of the study period, restricting the analysis of this pollutant to 700 days. The pollutant gases were maximum daily 1 hour nitrogen dioxide $\left(\mathrm{NO}_{2}\right)$ (four sites), mean 24 hour sulphur dioxide $\left(\mathrm{SO}_{2}\right)$ (five sites), maximum 8 hour moving average ozone $\left(\mathrm{O}_{3}\right.$, two sites) and maximum 8 hour moving average carbon monoxide (CO, two sites) The correlations between the sites ranged from 0.89 to 0.99 for $\mathrm{PM}_{10} ; 0.56$ to 0.78 for black smoke; 0.77 for sulphate; 0.70 to 0.86 for $\mathrm{NO}_{2} ; 0.48$ to 0.91 for $\mathrm{SO}_{2} ; 0.93$ for $\mathrm{O}_{3}$; and 0.83 for $\mathrm{CO}$. The means of the hourly maximal and minimal temperature and humidity at 0600 and 1500 were calculated for each day from data provided by the Meteorological Office and the University of Birmingham.

We used the statistical approach adopted by the second stage of the current joint European study of the short term effects of air pollution (APHEA 2). Regression with a quasilikelihood approach was used to model the association between pollution and the daily number of deaths or admissions after controlling for effects of seasonal patterns, temperature and humidity, influenza episodes, day of the week, and holidays. Generalised additive models were used to allow for the non-linear dependence of the outcome measures on some explanatory variables. Particular attention was paid to the relations with temperature and relative humidity. The most appropriate functional forms, parametric or non-parametric, of temperature and humidity on the same day and previous few days were investigated and compared. Those which minimised Akaike's information criterion ${ }^{15}$ were selected for inclusion in the model. Finally, the pollution measures were added in turn and the SEs were adjusted for overdispersion (assumed constant over time) and any remaining serial correlation by the inclusion of autoregressive terms up to lag 4 days as necessary. The analyses were carried out in S-Plus 4.5 Professional.

Based on published work from the United Kingdom and elsewhere, we adopted the initial hypothesis of an association at the mean of lags $0+1$. However, individual lags from day 0 to day 3 were all examined, as well as the other cumulative lags, mean $0+1+2$ and mean $0+1+2+3$. The results of all these are available from the authors. The pollutants were fitted as linear terms. The statistical technique used gives a relative risk estimate for a pollution effect together with an SE, which indicates the precision of the estimate. To facilitate the comparison between different pollutants, the relative risk is presented as a percentage change in 
Table 1 Environmental variables

\begin{tabular}{|c|c|c|c|c|c|c|c|c|}
\hline & Days & Mean & $S D$ & Min & 10th & Median & 90th & $\operatorname{Max}$ \\
\hline \multicolumn{9}{|l|}{ Measured particles: } \\
\hline $\mathrm{PM}_{10}\left(\mu \mathrm{g} / \mathrm{m}^{3}\right) 24 \mathrm{~h}$ & 823 & 23.3 & 12.9 & 4.0 & 11.4 & 20.0 & 38.3 & 102.3 \\
\hline $\mathrm{PM}_{2.5}\left(\mu \mathrm{g} / \mathrm{m}^{3}\right) 24 \mathrm{~h}$ & 675 & 14.5 & 9.7 & 2.1 & 6.0 & 11.7 & 25.8 & 82.8 \\
\hline $\mathrm{PM}_{2.5-10}\left(\mu \mathrm{g} / \mathrm{m}^{3}\right) 24 \mathrm{~h}$ & 669 & 9.0 & 4.6 & 1.0 & 4.1 & 8.0 & 15.2 & 35.4 \\
\hline $\mathrm{BS}\left(\mu \mathrm{g} / \mathrm{m}^{3}\right) 24 \mathrm{~h}$ & 823 & 13.2 & 9.0 & 1.8 & 5.1 & 10.9 & 23.6 & 71.9 \\
\hline $\mathrm{SO}_{4}{ }^{2-}\left(\mu \mathrm{g} / \mathrm{m}^{3}\right) 24 \mathrm{~h}$ & 814 & 3.7 & 3.1 & 0.5 & 1.3 & 2.7 & 7.7 & 22.6 \\
\hline \multicolumn{9}{|l|}{ Measured gases: } \\
\hline $\mathrm{NO}_{2}(\mathrm{ppb}) \max 1 \mathrm{~h}$ & 823 & 37.2 & 15.1 & 10.7 & 22.9 & 34.9 & 51.7 & 176.1 \\
\hline $\mathrm{O}_{3}(\mathrm{ppb}) \max 8 \mathrm{~h}$ & 823 & 24.0 & 13.8 & 0.4 & 6.7 & 24 & 37.5 & 89.9 \\
\hline $\mathrm{SO}_{2}(\mathrm{ppb}) 24 \mathrm{~h}$ & 823 & 7.2 & 4.7 & 1.9 & 3.3 & 5.8 & 12.3 & 59.8 \\
\hline $\mathrm{CO}(\mathrm{ppm}) \max 8 \mathrm{~h}$ & 821 & 0.8 & 0.7 & 0.2 & 0.3 & 0.6 & 1.3 & 10.0 \\
\hline Mean temperature $\left({ }^{\circ} \mathrm{C}\right)$ & 823 & 9.3 & 5.2 & -3.4 & 2.4 & 9.3 & 16.1 & 22.6 \\
\hline Mean humidity (\%) & 823 & 78.7 & 10.0 & 51.0 & 65.5 & 79.5 & 91.5 & 99.0 \\
\hline
\end{tabular}

daily mortality or admissions associated with a change in pollutant from the 10th to 90th percentile of its ambient range. The original $\beta$ coefficient and its SE may be calculated from these data if desired. With so many analyses it is expected that significant associations will arise by chance. This problem was addressed partly by adopting an initial hypothesis for the lag (mean of days $0+1$ ) but we also took into account the size and direction of the estimates, strength of significance ( $1 \%$ rather than $5 \%$ ), and pattern of the lag distribution.

\section{Results}

The mean (SD) daily counts of deaths from all causes, cardiovascular causes, and respiratory causes were 61 (11), 28 (7), and 10 (5), respectively. The mean daily counts for cardiovascular and respiratory admissions were 71 (15) and 66 (23) respectively. The environmental data are shown in table 1 . Concentrations of $\mathrm{PM}_{10}$ were quite low compared with the current United Kingdom standard of $50 \mu \mathrm{g} / \mathrm{m}^{3}$, with a mean of 23 and maximum of 102 . The $\mathrm{PM}_{2.5}$ concentrations were about two thirds of those of $\mathrm{PM}_{10}$, with a mean of 15 and maximum of 83 . The correlations between the various pollutants are shown in table $2 . \mathrm{PM}_{2.5}$ correlated highly with $\mathrm{PM}_{10}(r=0.92)$, moderately highly with $\mathrm{SO}_{4}{ }^{2-}$, and black smoke $(r=0.64$ and 0.67 , respectively), and poorly with the $\mathrm{PM}_{2.5-10}(r=0.34) . \mathrm{PM}_{2.5-10}$ was only weakly associated with black smoke $(r=0.18)$, and $\mathrm{SO}_{4}{ }^{2-}(r=0.10) . \mathrm{PM}_{2.5}$ was consistently more strongly associated with $\mathrm{NO}_{2}, \mathrm{SO}_{2}$, and $\mathrm{CO}$ than was $\mathrm{PM}_{2.5-10}$.

\section{MORTALITY}

The results for all cause mortality are shown in table 3. There were no strongly significant associations $(p<0.01)$ and the only association significant at the $5 \%$ level was with ozone. There was, however, evidence of a significant interaction with season for all the particle measures, all of which showed positive associations $(p<0.01)$ in the warm season (fig 1). In the cool season, the associations were negative but none were significant at the $1 \%$ level. For the gases, the most important seasonal interactions were with ozone and $\mathrm{NO}_{2}$, both of which showed significant positive associations in the warm season. For cardiovascular mortality, there were no associations with any of the particle measures. The largest associations were with $\mathrm{CO}$ and $\mathrm{NO}_{2}$, with $\mathrm{CO}$ only significant at the $5 \%$ level. There were no significant

Table 2 Correlations (Pearson correlation coefficient) between environmental variables

\begin{tabular}{|c|c|c|c|c|c|c|c|c|c|}
\hline & $P M_{10}$ & $P M_{2.5}$ & $P M_{2.5-10}$ & $B S$ & $\mathrm{SO}_{4}^{2-}$ & $\mathrm{NO}_{2}$ & $\mathrm{O}_{3}$ & $\mathrm{SO}_{2}$ & $\mathrm{CO}$ \\
\hline $\mathrm{PM}_{2.5}$ & 0.92 & & & & & & & & \\
\hline $\mathrm{PM}_{2.5-10}$ & 0.56 & 0.34 & & & & & & & \\
\hline BS & 0.64 & 0.67 & 0.18 & & & & & & \\
\hline $\mathrm{SO}_{4}{ }^{2-}$ & 0.64 & 0.64 & 0.10 & 0.30 & & & & & \\
\hline $\mathrm{NO}_{2}$ & 0.62 & 0.61 & 0.25 & 0.65 & 0.30 & & & & \\
\hline $\mathrm{O}_{3}$ & -0.06 & -0.11 & 0.19 & -0.35 & 0.00 & 0.08 & & & \\
\hline $\mathrm{SO}_{2}$ & 0.55 & 0.52 & 0.31 & 0.50 & 0.19 & 0.52 & -0.22 & & \\
\hline $\mathrm{CO}$ & 0.55 & 0.54 & 0.10 & 0.77 & 0.17 & 0.73 & -0.29 & 0.49 & \\
\hline Temperature & -0.06 & -0.15 & 0.21 & -0.24 & -0.08 & -0.06 & 0.44 & -0.13 & -0.19 \\
\hline Humidity & -0.06 & 0.08 & -0.32 & 0.18 & 0.10 & -0.09 & -0.59 & -0.13 & -0.19 \\
\hline
\end{tabular}

Table 3 Pollution and daily mortality for all causes, cardiovascular and respiratory causes (\% change (95\% CI) for pollution increment 10-90th percentile, mean lag $0+1$ days)

\begin{tabular}{|c|c|c|c|c|c|c|c|c|c|c|}
\hline Pollutant & $\begin{array}{l}\text { 10-90th } \\
\text { Percentile }\end{array}$ & $\begin{array}{l}\text { All causes } \\
\%(95 \% \text { CI })\end{array}$ & $p$ Value & $\begin{array}{l}\text { Interaction } \\
\text { with season } \\
\text { p Value }\end{array}$ & $\begin{array}{l}\text { Cardiovascular } \\
\text { causes } \\
\%(95 \% \text { CI })\end{array}$ & $p$ Value & $\begin{array}{l}\text { Interaction } \\
\text { with season * } \\
\text { p Value }\end{array}$ & $\begin{array}{l}\text { Respiratory causes } \\
\%(95 \% C I)\end{array}$ & $p$ Value & $\begin{array}{l}\text { Interaction } \\
\text { with season* } \\
\text { p value }\end{array}$ \\
\hline $\mathrm{PM}_{10}$ & 24.4 & $0.2(-1.8$ to 2.2$)$ & 0.9 & 0.007 & $1.0(-1.9$ to 4.0$)$ & 0.5 & 0.5 & $-1.4(-6.0$ to 3.5$)$ & 0.6 & 0.2 \\
\hline $\mathrm{PM}_{25}$ & 17.7 & $0.6(-1.5$ to 2.7$)$ & 0.6 & 0.01 & $0.9(-2.1$ to 4.0$)$ & 0.6 & 0.7 & $-0.1(-5.4$ to 5.5$)$ & 0.98 & 0.1 \\
\hline $\mathrm{PM}_{2.5-10}$ & 11.3 & $-0.6(-4.2$ to 2.3$)$ & 0.7 & 0.01 & $-0.8(-4.8$ to 3.5$)$ & 0.7 & 0.2 & $-7.6(-13.9$ to -0.9$)$ & 0.03 & 0.06 \\
\hline BS & 16.7 & $0.6(-1.5$ to 2.7$)$ & 0.6 & 0.003 & $1.5(-1.5$ to 4.7$)$ & 0.3 & 0.5 & $0.1(-4.8$ to 5.2$)$ & 0.97 & 0.04 \\
\hline $\mathrm{SO}_{4}{ }^{2-}$ & 5.8 & $-0.4(-2.3$ to 1.5$)$ & 0.7 & 0.001 & $-1.3(-4.0$ to 1.5$)$ & 0.4 & 0.2 & $-1.8(-6.4$ to 3.0$)$ & 0.5 & 0.2 \\
\hline $\mathrm{NO}_{2}$ & 25.5 & $1.4(-0.4$ to 3.2$)$ & 0.1 & 0.04 & $2.6(-0.1$ to 5.4$)$ & 0.06 & 0.6 & $2.8(-1.6$ to 7.5$)$ & 0.2 & 0.3 \\
\hline $\mathrm{O}_{3}$ & 28.6 & $2.9(-0.1$ to 6.0$)$ & 0.05 & 0.01 & $0.9(-3.4$ to 5.4$)$ & 0.7 & 0.1 & $2.2(-5.4$ to 10.4$)$ & 0.6 & 0.1 \\
\hline $\mathrm{SO}_{2}$ & 8.5 & $-0.2(-2.1$ to 1.8$)$ & 0.8 & 0.9 & $-0.2(-3.0$ to 2.6$)$ & 0.9 & 0.2 & $-1.9(-6.3$ to 2.7$)$ & 0.4 & 0.4 \\
\hline $\mathrm{CO}^{2}$ & 1.0 & $0.8(-0.6$ to 2.2$)$ & 0.3 & 0.2 & $2.5(0.4$ to 4.6$)$ & 0.02 & 0.8 & $1.2(-2.1$ to 4.6$)$ & 0.5 & 0.3 \\
\hline
\end{tabular}

^Significance of interaction term for warm (April-September) and cool (October-March) seasons. 


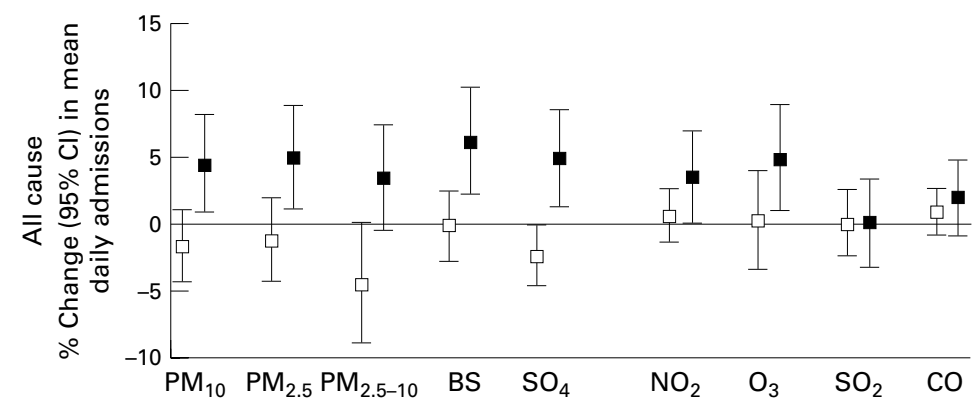

Figure 1 Cool (open square) and warm (black square) season estimates for effects of pollutants on daily mortality. Percentage change (95\% CI) for a 10th-90th percentile change in pollutant.

seasonal interactions. For all year respiratory mortality, there was no convincing evidence of positive associations with any measure of particles or gases. The most notable finding was a large negative association with $\mathrm{PM}_{2.5-10}(-7.6 \%$, $95 \%$ confidence interval $(95 \% \mathrm{CI})-13.9$ to $-0.9)$. The only significant seasonal interaction was for black smoke, which showed a positive association in the warm season at the $5 \%$ level $(9.4 \%, 95 \%$ CI 0.0 to 19.7$)$.

ADMISSIONS

In the all year analysis of cardiovascular admissions, and the subdiagnoses of cardiac diseases and ischaemic heart disease, effect estimates
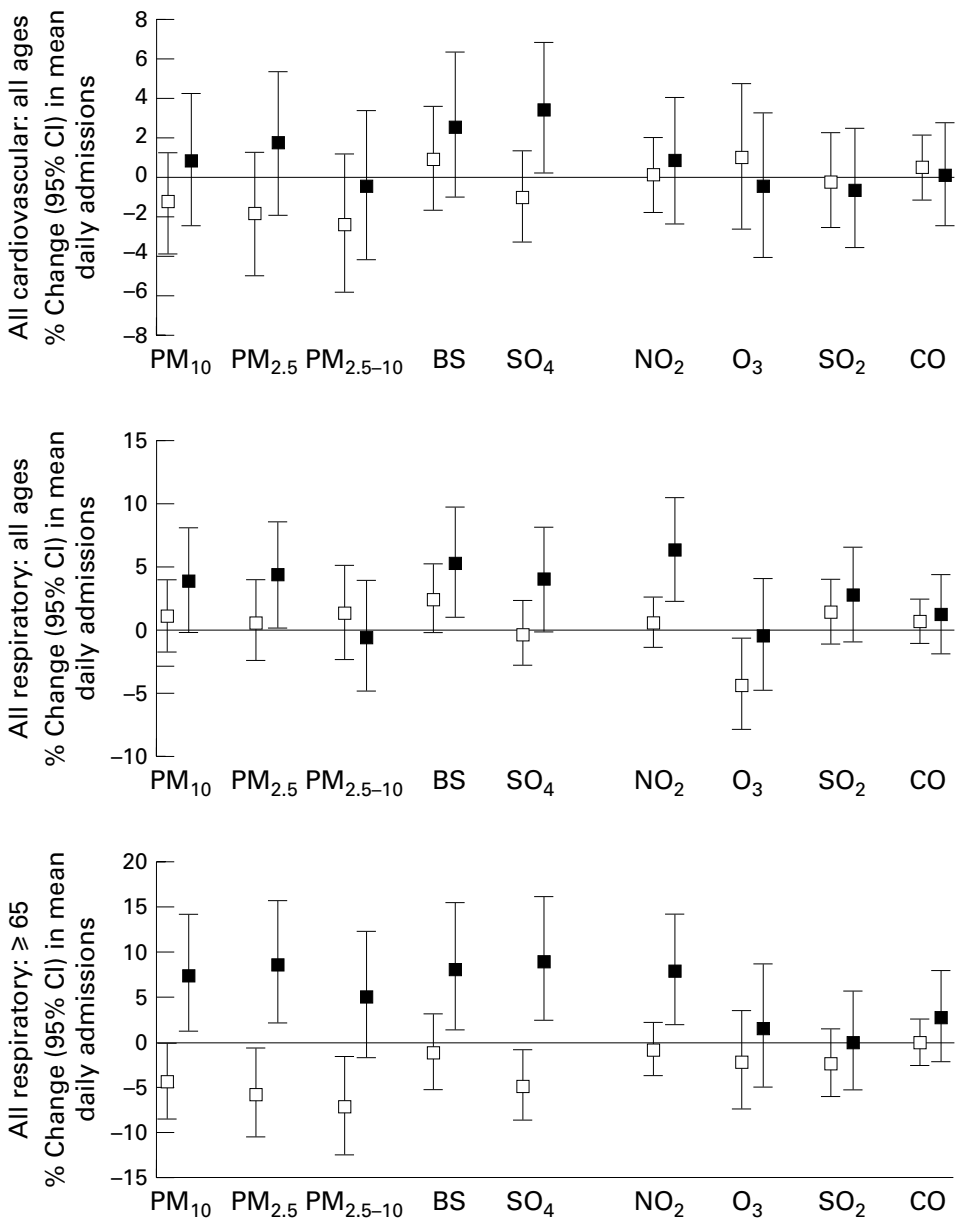

Figure 2 Cool (open square) and warm (black square) season estimates for effects of pollutants on daily admissions for cardiovascular and respiratory disease. Percentage change (95\% CI) for a 10th-90th percentile change in pollutant. were not significant and there was no consistency in the direction of effect (table 4). There was a significant seasonal interaction with sulphate which showed a weak positive association in the warm season $(3.4 \%, 95 \%$ CI 0.2 to 6.8 , fig 2). For stroke, the main findings were a strong negative association with coarse particles and a weak positive association with $\mathrm{SO}_{2}$.

The relative risks for all respiratory admissions are shown in table 5 and compared by season in fig 2 . In the all ages group, there were no significant associations with particles or gases. There was a significant seasonal interaction for $\mathrm{NO}_{2}$ only. There were weak positive associations with $\mathrm{PM}_{2.5}$, black smoke, and $\mathrm{NO}_{2}$ in the warm season and a weak negative association with ozone in the winter. In the $0-14$ age group there was a very strong positive association with $\mathrm{SO}_{2}$, weak positive associations with $\mathrm{PM}_{10}, \mathrm{PM}_{2.5}$, and black smoke, and a weak negative association with ozone. There were no significant seasonal interactions.

There was little evidence of any associations in the 15-64 age group in either the all year or seasonal analysis. In the $\geqslant 65$ group, nearly all of the associations with respiratory admissions were negative, but none approached even weak significance. There was, however, a striking seasonal interaction with large negative associations in the cool season and large positive associations in the warm season (fig 2). Most of the associations that were significant at the $1 \%$ level were positive and occurred in the warm season $\left(\mathrm{PM}_{2.5}, \mathrm{SO}_{4}{ }^{2-}, \mathrm{NO}_{2}\right)$, but a notable exception was a large negative association with $\mathrm{PM}_{2.5-10}$ in the winter that resembled the negative winter association with respiratory mortality.

Selected results for admissions due to asthma and chronic obstructive pulmonary disease (COPD) are shown in table 6. For asthma in 0-14 year old children, the largest association was a negative one with ozone $(-12.9 \%, 95 \%$ CI -21.2 to -3.8$)$, followed by large positive associations with $\mathrm{SO}_{2}(10.9 \%$, $95 \%$ CI 4.5 to 17.8$)$ and $\mathrm{PM}_{10}(8.3 \%, 95 \% \mathrm{CI}$ 1.7 to 15.3 ), all of which were significant at the $1 \%$ level or higher. There was little evidence of any seasonal interaction. In the 15-64 age group, all of the estimates for asthma were negative, but were none the less consistent with the possibility of no effect at the $1 \%$ level of significance. There were no significant seasonal interactions. For COPD admissions, no effects or major seasonal interactions were found.

PARTICLE CHARACTERISTICS

It was not possible to discern an obvious difference between the effects of $\mathrm{PM}_{2.5}$ and $\mathrm{PM}_{10}$ which is not surprising as $\mathrm{PM}_{2.5}$ is about two thirds of $\mathrm{PM}_{10}$ and the two measures were highly correlated. $\mathrm{PM}_{2.5}$ tended to have effects of a similar size and direction to those of black smoke and sulphate. There were, however, indications that the $\mathrm{PM}_{2.5}$ associations did not parallel those of the coarse fraction, $\mathrm{PM}_{2.5-10}$, and in some instances were in opposite directions. Analyses with two pollutant models were not attempted for the mortality series because so few associations were found. Two 

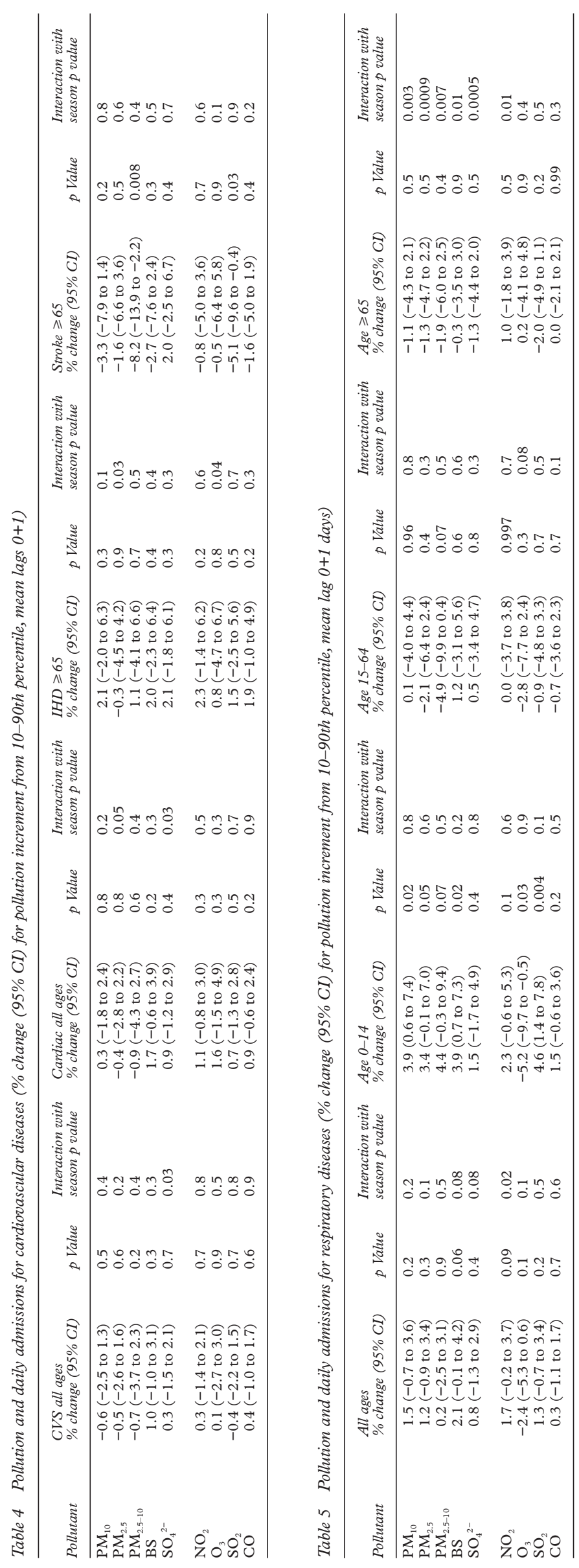

pollutant models were constructed for all ages and $0-14$ year old respiratory admissions. It was found that the effects of $\mathrm{PM}_{2.5}$ were considerably reduced when black smoke was included in the model, but were relatively unaffected by inclusion of $\mathrm{PM}_{2.5-10}$ or $\mathrm{SO}_{4}{ }^{2-}$. The effects of black smoke were generally unaffected by inclusion of any of the other particle measures in the model. $\mathrm{SO}_{4}{ }^{2-}$ tended to be reduced by the inclusion of $\mathrm{PM}_{2.5}$. The results for $\mathrm{PM}_{2.5-10}$ were inconsistent for the two outcomes shown. Overall, the most notable result was the stability of the black smoke estimate together with increased significance when other particle measures were included in the black smoke model. For all respiratory admissions-for example, the percentage changes for a 10th-90th percentile increment of black smoke-were black smoke 2.1 (95\% CI -0.1 to 4.2$)$, black smoke+PM ${ }_{2.5} 3.8$ (0.5 to 7.3), black smoke+PM ${ }_{2.5-10} 2.9$ (0.5 to 5.3), and black smoke $+\mathrm{SO}_{4}{ }^{2-} 2.4$ (0.1 to 4.7$)$. We also compared the different particles by their lag patterns (data not shown). The $\mathrm{PM}_{2.5}$ pattern closely resembled that of $\mathrm{PM}_{10}$ and black smoke whereas that of $\mathrm{PM}_{2.5-10}$ tended to be inconsistent.

\section{Discussion}

The overall impression from the analysis of the main all year, all age series of mortality and admissions is that there is little evidence for associations with either particles or gases although most associations are positive in direction. The estimates, although small, were within the ranges estimated for $\mathrm{PM}_{10}$ and black smoke by previous studies in Birmingham ${ }^{16}$ and London. ${ }^{17}{ }^{18}$ Except for PM $_{2.5-10}$, there were strong seasonal interactions in the mortality analysis with all measures of particles showing significant associations in the warm season. By contrast, there was little evidence of seasonal interactions in the admissions analysis, although some significant warm season associations with particles and $\mathrm{NO}_{2}$ were found which were driven mainly by associations in the $\geqslant 65$ age group. When admissions were analysed by subgroup, associations did emerge between respiratory and asthma admissions in the 0-14 age group and $\mathrm{PM}_{10}, \mathrm{PM}_{2.5}$, black smoke, $\mathrm{SO}_{2}$ (positive), and $\mathrm{O}_{3}$ (negative). There was little evidence for any effects on mortality or admissions for cardiovascular diseases or subgroups thereof (cardiac, ischaemic heart disease, stroke). There were several negative associations, notably in the cool season with admissions and mortality for respiratory disease in elderly people. The largest negative association was between coarse particles and respiratory mortality.

Our findings of small associations which could be explained as chance effects is not typical of other reported studies, but not unusual. We do not think that our results can be attributed to the statistical techniques employed, as these were those currently used by others around the world including the APHEA project, and which have been found to be satisfactory and reasonably robust. ${ }^{19}$ We did examine the sensitivity of several series to different 
Table 6 Pollution and daily admissions for asthma and COPD (\% change (95\% CI) for pollution increment from 10-90th percentile, mean lag 0+1 days)

\begin{tabular}{|c|c|c|c|c|c|c|c|c|c|}
\hline Pollutant & $\begin{array}{l}\text { Asthma age } 0-14 \\
\% \text { change }(95 \% \text { CI) }\end{array}$ & $p$ Value & $\begin{array}{l}\text { Interaction } \\
\text { with season } \\
\text { p value }\end{array}$ & $\begin{array}{l}\text { Asthma age } 15-64 \\
\% \text { change }(95 \% \text { CI) }\end{array}$ & $p$ Value & $\begin{array}{l}\text { Interaction } \\
\text { with season } \\
p \text { value }\end{array}$ & $\begin{array}{l}\text { COPD age } \geqslant 65 \\
\% \text { change }(95 \% \text { CI })\end{array}$ & $p$ Value & $\begin{array}{l}\text { Interaction } \\
\text { with season } \\
\text { p value }\end{array}$ \\
\hline $\mathrm{PM}_{10}$ & $8.3(1.7$ to 15.3$)$ & 0.01 & 0.03 & $-2.3(-10.0$ to 6.1$)$ & 0.6 & 0.9 & $-1.8(-6.9$ to 3.5$)$ & 0.5 & 0.3 \\
\hline $\mathrm{PM}_{2.5}$ & $6.0(-0.9$ to 13.4$)$ & 0.09 & 0.03 & $-8.4(-16.3$ to 0.3$)$ & 0.06 & 0.9 & $-3.9(-9.0$ to 1.6$)$ & 0.2 & 0.3 \\
\hline $\mathrm{PM}_{2.5-10}$ & $7.1(-2.1$ to 17.2$)$ & 0.1 & 0.4 & $-10.7(-19.9$ to -0.5$)$ & 0.04 & 0.3 & $-1.7(-8.9$ to 5.3$)$ & 0.6 & 0.8 \\
\hline BS & $7.4(0.7$ to 14.5$)$ & 0.03 & 0.09 & $-2.8(-10.7$ to 5.8$)$ & 0.5 & 0.1 & $1.5(-3.7$ to 7.0$)$ & 0.6 & 0.1 \\
\hline $\mathrm{SO}_{4}{ }^{2-}$ & $2.1(-3.9$ to 8.6$)$ & 0.5 & 0.9 & $-4.2(-11.7$ to 3.9$)$ & 0.3 & 0.9 & $-0.3(-5.3$ to 4.9$)$ & 0.9 & 0.05 \\
\hline $\mathrm{NO}_{2}$ & $4.0(-2.0$ to 10.2$)$ & 0.2 & 0.4 & $-3.3(-10.4$ to 4.4$)$ & 0.4 & 0.7 & $2.5(-2.1$ to 7.3$)$ & 0.3 & 0.2 \\
\hline $\mathrm{O}_{3}$ & $-12.9(-21.2$ to -3.8$)$ & 0.007 & 0.02 & $-1.7(-11.2$ to 8.9$)$ & 0.8 & 0.9 & $0.2(-7.0$ to 8.0$)$ & 0.1 & 0.7 \\
\hline $\mathrm{SO}_{2}$ & $10.9(4.5$ to 17.8$)$ & 0.0007 & 0.0006 & $2.4(-5.5$ to 10.9$)$ & 0.6 & 0.9 & $-4.2(-8.9$ to 0.8$)$ & 0.1 & 0.4 \\
\hline $\mathrm{CO}$ & $3.9(-0.5$ to 8.5$)$ & 0.08 & 0.04 & $-4.9(-10.6$ to 1.1$)$ & 0.1 & 0.03 & $1.0(-2.5$ to 4.6$)$ & 0.6 & 0.7 \\
\hline
\end{tabular}

ways of controlling for confounding due to season and meteorological factors, including the use of parametric methods, and obtained the same order of results. The large negative associations were not created by the analysis but were in the raw correlations and persisted despite careful control for confounders. It may be relevant that the daily variation in concentrations of pollutants was considerably less than found in some other studies and that the series was relatively short.

We systematically analysed many series, which makes it more likely that our results will be heterogeneous by chance alone. Therefore, in comparing our results with those of other studies, it must be noted that we did not choose the best estimate from a variety of lags, but adopted an initial approach that used the mean of the current and previous day's pollution. Use of the best estimate approach would have led to many significant results, although the sizes of estimates may not have been affected materially because estimates at different lags tend to be correlated. The inclusion of seasonal results made interpretation even more complex and for this reason, we tended to emphasise only those seasonal associations accompanied by evidence of a significant seasonal interaction. Due to all these considerations, we adopted a higher level of significance $(1 \%)$ in attempting to identify the results that were least likely to be due to chance.

The small and non-significant associations with particles in the all year analyses contrast with the general picture of larger and often significant associations reported elsewhere in the United Kingdom, Europe, and beyond. However, the $95 \%$ CIs for the present associations overlap the estimates for previous United Kingdom studies (including one in Birmingham), and estimates from meta-analyses from United States and European cities, and our results do not in themselves contradict the weight of evidence in favour of associations between PM and daily mortality and hospital admissions. The seasonal differences are also of interest because if there is a linear exposureresponse relation, relative risks would not be expected to be different across the seasons. Possible reasons, none of which can be explored in our data, include seasonal differences in pollutant mixtures and interactions, differences in vulnerability, and differences in exposure due to seasonal lifestyle factors.

The main purpose of the analysis was to see if the effects of different measures of particles could be differentiated. This was hampered by the rather small and variable effects found and no clear pattern emerged. There were indications however that $\mathrm{PM}_{2.5}$ was more consistently positively associated with health effects than $\mathrm{PM}_{2.5-10}$. $\mathrm{PM}_{2.5}$ comprises primary and secondary components, according to their origin. ${ }^{4} 20$ Primary particles are created directly by local combustion processes in or near the area studied. These particles tend to be carbonaceous and are indicated well by the black smoke technique which detects fine black particles. In the west Midlands area, the main source of black smoke is diesel exhaust. The reflectance method used for measuring black smoke was calibrated to a gravimetric standard based on pollution from coal burning, so may not be accurate where the main source of black particles is diesel exhaust emissions. However, our findings suggest that black smoke represents an important active component of $\mathrm{PM}_{10}$ and $\mathrm{PM}_{2.5}$. It would be useful if a more standardised method of measuring black primary particles from vehicle exhaust could be developed. The other component of $\mathrm{PM}_{25}$ is secondary particles, formed by atmospheric reactions which take place at a distance from the primary emission source. Sulphate is formed from the atmospheric oxidation of sulphur dioxide. In summer this is predominantly by reaction with the hydroxyl free radical. In winter it is through solution phase oxidation by ozone and hydrogen peroxide forming initially sulphuric acid, which is then, in the United Kingdom, neutralised by ammonia. In eastern North America, where there is less neutralisation, it is more likely to be associated with free acid aerosol. Sulphate itself is unlikely to be toxic but could be a carrier for other potentially bioactive substances such as transition elements. However, we found few associations between sulphate and health outcomes and can draw no firm conclusion about its effects on health. Ammonium nitrate is another major component of secondary particles in the atmosphere of the United Kingdom that is derived from oxidisation of nitrogen dioxide. It was not included explicitly in this study as measurements were not available. Nitrate concentrations tend to correlate strongly with sulphate in the atmosphere of the United Kingdom, and due to its semivolatile nature, ammonium nitrate is not collected by the tapered element oscillating microbalance samplers used for measurement of $\mathrm{PM}_{10}$ in the United Kingdom automatic networks. It is therefore not taken 
into account in the measurements of $\mathrm{PM}_{2.5}$ and $\mathrm{PM}_{10}$ used in this research.

Some of the most variable results were obtained for $\mathrm{PM}_{2.5-10}$, and these included some strong negative associations with respiratory mortality and stroke. The $\mathrm{PM}_{2.5-10}$ is created mainly from resuspended crustal materials, rather than combustion. This so called coarse fraction comprises particles of a diameter equivalent to the smallest airways $(10 \mu \mathrm{m})$ which are thought to be deposited relatively more in the larger airways than are fine particles. Because fine particles have greater proportional penetration of the lung and because of theories that particle numbers may be most important, ${ }^{21}$ the possible effects of the coarse fraction have tended to be ignored, to the extent that monitoring of $\mathrm{PM}_{2.5}$ instead of $\mathrm{PM}_{10}$ is being considered by some authorities. However, the epidemiological evidence is mixed. Some studies find a clear difference between $\mathrm{PM}_{2.5}$ and $\mathrm{PM}_{2.5-10},{ }^{12} 1322$ and some no difference. ${ }^{7}{ }^{2.5}$ Some studies have even found a greater effect of coarse particles. ${ }^{1023}$ However, Ostro et $a l^{4}$ reported associations between daily mortality and coarse particles in a desert region of California, whereas Schwartz found no association between $\mathrm{PM}_{10}$ due to dust storms in Spokane, WA, USA. ${ }^{25}$ A metaanalysis of 29 cities found that the sizes of associations of $\mathrm{PM}_{10}$ with daily mortality were positively associated with the annual average $\mathrm{PM}_{2.5} / \mathrm{PM}_{10}$ ratio, which supports $\mathrm{PM}_{2.5}$ as being a key component of $\mathrm{PM}_{10}$. In our study, the most prominent differences between the coarse and fine fractions arose because of some large negative effects of $\mathrm{PM}_{2.5-10}$ in subgroup analyses of respiratory admissions. These negative relations were not created by the analysis as they were present in the nonseasonally adjusted correlations. On theoretical grounds it seems unlikely that the coarse fraction is protective in which case negative confounding may be an explanation. This could occur because the coarse fraction, being composed of resuspended material, is higher on windy days in Birmingham. ${ }^{26}$ On such days dispersal of locally emitted fine particles would tend to be higher resulting in lower ambient concentrations of the finer more toxic particles. Recent work from the Birmingham area points to a complex interrelation between synoptic weather patterns, air pollution, and daily respiratory admissions ${ }^{27}$ which could also be a source of negative confounding.

We conclude that in this population clear effects of particulate air pollution on daily mortality and admissions are difficult to discern, as are the relative effects of individual components of the mixture. Within these limitations, the results suggest that $(a)$ the active component of $\mathrm{PM}_{10}$ resides mainly in the fine fraction and that this is due in part to primary particles indicated by black smoke; $(b)$ effects are stronger in the warm season; $(c)$ there is also evidence for an effect of secondary particles; $(d)$ effects of the coarse fraction cannot be excluded; and (e) some unexplained negative effects found in the cool season require further investigation.
This work was funded by the United Kingdom Department of Health. We are grateful for the advice and comments of members of the Expert Panel on Air Quality Standards (chairman, Anthony Seaton)

1 United States Environmental Protection Agency. Air quality criteria for particulate matter. Research Triangle Park NC: USEPA, 1996.

2 Department of Health Committee on the Medical Effects of Air Pollutants. Non-biological particles and health. London: The Stationery Office, 1995.

3 Pope CA3, Dockery DW. Epidemiology of particle effects. In: Holgate ST, Samet JM, Koren HS, et al, editors. Air pollution and health. London: Academic Press, 1999:673-706.

4 Airborne Particles Expert Group (APEG). Source apportionment of airborne particulate matter in the United Kingdom. London: Department of the Environment Transport and the Regions, 1999.

5 Schwartz J, Dockery DW, Neas LM. Is daily mortality associated specifically with fine particles? I Air Waste Manage Assoc 1996;46:927-39.

6 Dockery DW, Schwartz J, Spengler JD. Air pollution and daily mortality: associations with particulates and acid aerosols. Environ Res 1992;59:362-73.

7 Thurston GD, Ito K, Hayes CG, et al. Respiratory hospital admissions and summertime haze air pollution in Toronto, Ontario: consideration of the role of acid aerosols. Environ Res 1994;65:271-90.

8 Burnett RT, Cakmak S, Brook JR, et al. The role of particulate size and chemistry in the association between summertime ambient air pollution and hospitalization for cardiorespiratory diseases. Environ Health Perspect 1997;105: 614-20.

9 Sheppard L, Levy D, Norris G, et al. Effects of ambient air pollution on non-elderly asthma hospital admissions in Seattle, Washington, 1987-94. Epidemiology 1999;10:2330.

10 Castellejos M, Borja-Aburto VH, Dockery DW, et al. Airborne coarse particles and mortality. Inhal Toxicol 2000; 12:61-72.

11 Levy JI, Hammitt JK, Spengler J. Estimating the mortality impacts of particulate matter: what can be learned from between-study variability? Environ Health Perspect 2000; 108:109-17.

12 Schwartz J, Neas LM. Fine particles are more strongly associated than coarse particles with acute respiratory health ciated than coarse particles with acute respiratory 10
effects in school children. Epidemiology 2000;11:6-10.

13 Gold DR, Damokosh AI, Pope CA, et al. Particulate and ozone pollutant effects on the respiratory function of children in southwest Mexico City. Epidemiology 1999;10:816.

14 Tiittanen P, Timonen KL, Ruuskanen J, et al. Fine particulate air pollution, resuspended road dust and respiratory health among symptomatic children. Eur Respir f 1999;13: health a $266-73$.

15 Akaike $\mathrm{H}$. Information theory and an extension of the maximum likelihood principal. In: Petros BN, Csaki F, eds. 2nd International Symposium on information Theory. Budapest: Akademiai Kiado, 1973.

16 Wordley J, Walters S, Ayres JG. Short term variations in hospital admissions and mortality and particulate air pollution Occup Environ Med 1997:54:108-16.

17 Atkinson RW, Bremner SA, Anderson HR, et al. Short-term associations between emergency hospital admissions for respiratory and cardiovascular disease and outdoor air pollution in London. Arch Environ Health 1999;54:398-411.

18 Bremner SA, Anderson HR, Atkinson RW, et al. Short term associations between outdoor air pollution and mortality in London 1992-4. Occup Environ Med 1999;56:237-44.

19 Health Effects Institute. Particulate air pollution and daily mortality: analysis of the effects of weather and multiple air pollutants. Boston, MA: Health Effects Institute, 1997.

20 Wilson WE, Suh HH. Fine particles and coarse particles: concentration relationships relevant to epidemiologic studies. F Air Waste Manag Assoc 1997;47:1238-49.

21 Peters A, Wichmann HE, Tuch T, et al. Respiratory effects are associated with the number of ultrafine particles. Am f Respir Crit Care Med 1997;155:1376-83.

22 Schwartz J, Dockery DW, Neas LM. Is daily mortality associated specifically with fine particles? I Air Waste Manag Assoc 1996;46:927-39.

23 Loomis D. Sizing up air pollution research. Epidemiology 2000;11:2-4.

24 Ostro BD, Hurley S, Lipsett MJ. Air pollution and daily mortality in the Coachella valley, California: a study of $\mathrm{PM}_{10}$ dominated by coarse particles. Environ Res 1999;81: 231-8.

25 Schwartz J, Norris G, Larson T, et al. Episodes of high coarse particle concentrations are not associated with increased mortality. Environ Health Perspect 1999;107:339-42.

26 Harrison RM, Deacon AR, Jones MR, et al. Sources and processes affecting concentrations of $\mathrm{PM}_{10}$ and $\mathrm{PM}_{2.5}$ particulate matter in Birmingham, UK. Atmos Environ 1997;31:4103-17.

27 McGregor GR, Walters S, Wordley J. Daily hospital respiratory admissions and winter air mass types, Birmingham, UK. International fournal of Biometeorology 1999;43:21-30. 